\title{
Erratum to: One-stage immobilization of the microalga Porphyridium purpureum using a biocompatible silica precursor and study of the fluorescence of its pigments
}

\author{
S. S. Voznesenskiy ${ }^{1}$ A. Yu. Popik ${ }^{1,3}$ - E. L. Gamayunovov ${ }^{1,3}$ T. Yu. Orlova ${ }^{2}$ \\ Zh. V. Markina ${ }^{2}$ I. V. Postnova ${ }^{3,4}$ - Yu. A. Shchipunov ${ }^{4}$
}

Published online: 31 May 2017

(C) European Biophysical Societies' Association 2017

\section{Erratum to: Eur Biophys J \\ DOI 10.1007/s00249-017-1213-y}

In the original publication, the initials of the fifth and seventh author are incorrect. The correct initials with last name of the authors should read as given below, and the original article was corrected accordingly.

Zh. V. Markina and Yu. A. Shchipunov

The online version of the original article can be found under doi:10.1007/s00249-017-1213-y.

S. S. Voznesenskiy

vss@iacp.dvo.ru

1 Institute of Automation and Control Processes, FEB RAS, Vladivostok, Russia

2 National Scientific Centre of Marine Biology, FEB RAS, Vladivostok, Russia

3 Far Eastern Federal University, Vladivostok, Russia

4 Institute of Chemistry, FEB RAS, Vladivostok, Russia 